\title{
PathoBiochemistry-directed Guidelines for COVID-19
}

\author{
Yuliya Buinitskaya, $\mathrm{MD}^{1 *}$, Clifford G. Wlodaver, $\mathrm{MD}^{2}$, Roman Gurinovich ${ }^{1}$, and \\ Siarhei Kastsiuchenka, $\mathrm{MD}^{3}$ \\ 1 Sci.AI, Tallinn, Estonia \\ ${ }^{2}$ Oklahoma University Health Sciences Center, Oklahoma City, OK, United States, \\ ${ }^{3}$ Anesthesiology Institute, Cleveland Clinic Abu Dhabi, Abu Dhabi, United Arab Emirates \\ *corresponding author, e-mail: julia@sci.ai
}

\begin{abstract}
Patients with underlying health conditions are at risk for a poor outcome from Coronavirus disease 2019 (COVID-19). We investigated the pathobiochemistry of this observation to generate therapeutic guidelines. Using machine reasoning by the sci.AI system, facts were extracted and linked from publications available in nlm.nih.gov and Europe PMC to form the dataset which was validated by medical experts. Since preexisting chronic inflammation renders the acute inflammatory response to Severe acute respiratory syndrome coronavirus 2 (SARS-CoV-2) excessive translating the SARS-CoV-2 infection into the clinical COVID-19 syndrome, we focus on therapeutic interventions that mitigate the immune response. In essence, from bench to bedside, as depicted in the Graphical Abstract, the clinical management of COVID-19 should aim at:

A. Control of excessive oxidant production.

B. Neutralization of excessive oxidants.

C. Upregulation of nitric oxide (NO) production.
\end{abstract}

Key words: COVID-19 therapy, oxidant, antioxidant, nitric oxide (NO), thrombosis

\section{Background}

In follow-up to our articles on the pathogenesis of Coronavirus disease 2019 (COVID-19), [1, 2] we have written this article focusing on its clinical applications.

When the body receives an insult, whether infectious or non-infectious, it responds with inflammation that is promoted by the Prooxidant system (PO) through cytokines, e.g. tumor necrosis factor-alpha $(\mathrm{TNF} \alpha)$, generating the oxidant superoxide (O2-), a component of Reactive Oxygen Species (ROS), by NADPH oxidase. [3] However, oxidants can damage normal cells as well and the Antioxidant system (AO) defends the body by producing antioxidants. These two systems normally balance each other. The main antioxidants are glutathione (GSH) that neutralizes oxidants, and nitric oxide (NO) that inhibits its production through suppression of NADPH oxidase. [4] Both the PO and $\mathrm{AO}$ systems require the co-factor reduced form of nicotinamide adenine dinucleotide phosphate (NADPH) which is produced by glucose-6-phosphate dehydrogenase (G6PD). [5]

Severe acute respiratory syndrome coronavirus 2 (SARS-CoV-2) affects the body in two ways, as depicted in the Graphical Abstract (Fig.1): 


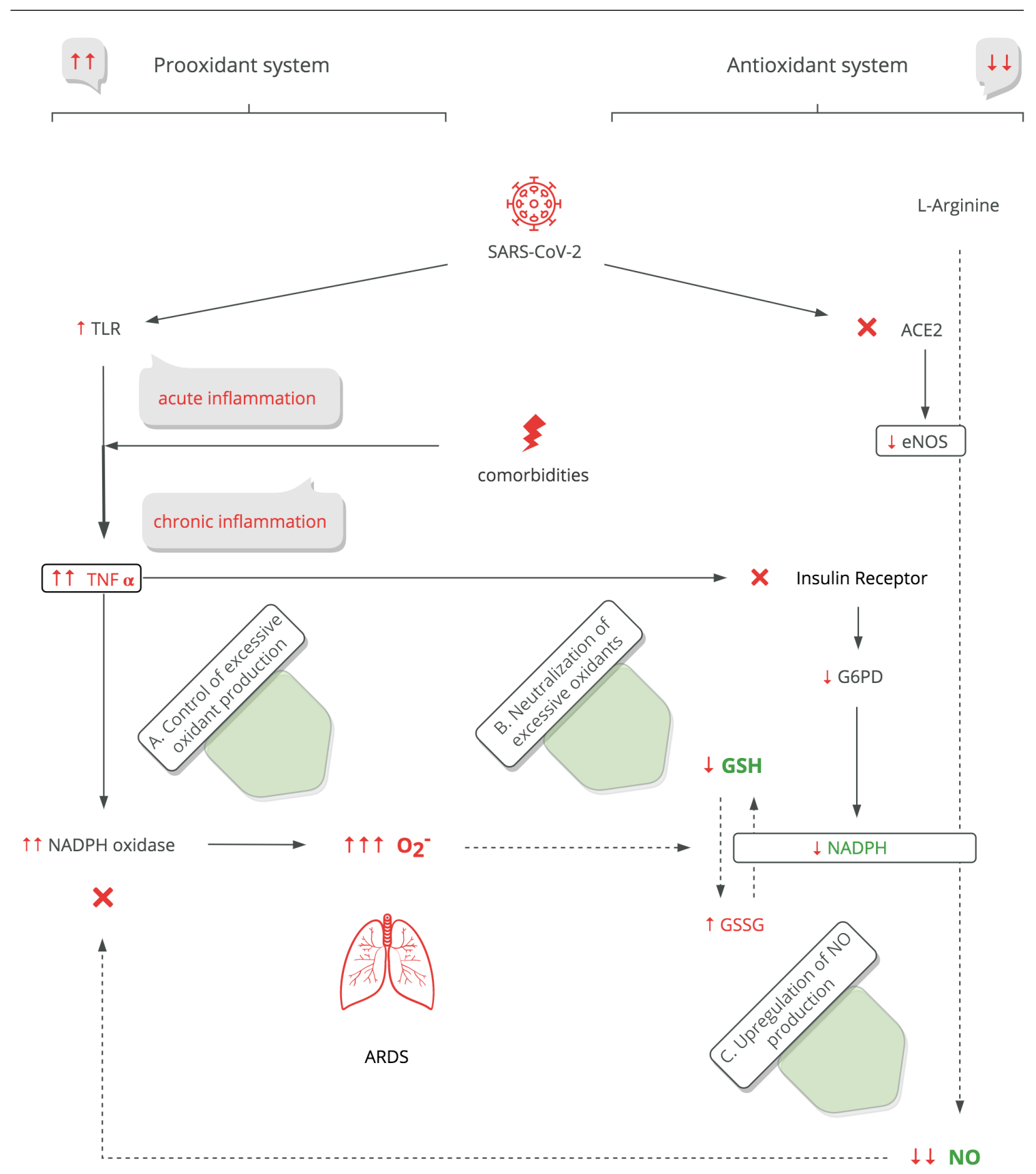

Fig. 1. Graphical Abstract 
1. Nonspecifically, as occurs for any pathogen, it triggers the PO system through activation of toll-like receptors (TLR), inducing an acute inflammatory immune response, [6] and

2. Specifically, it inhibits the AO system through suppression of the NO-producing angiotensinconverting enzyme 2 (ACE2) - endothelial nitric oxide synthase (eNOS) pathway. [7]

Chronic inflammation from non-infectious comorbidities, e.g. the metabolic syndrome, mediated through cytokines, continuously affects the body in two ways:

1. It triggers the PO system, and

2. It inhibits the AO system, through the inactivation of insulin receptors, [8] resulting in suppression of G6PD, and NADPH as a consequence.

Essentially, inflammation, whether it is acute or chronic, activates the PO and inhibits the AO systems. And preexisting chronic inflammation potentiates the acute inflammatory response to SARS-CoV-2. In addition, SARS-CoV-2 uniquely inhibits the AO system, rendering it excessive, also known as oxidative stress, cytokine storm, and systemic inflammatory response syndrome (SIRS). Excessive oxidants cause endothelial injury resulting in systemic edema and vasoconstriction. In the lungs, this manifests as Acute Respiratory Distress Syndrome (ARDS). [9]

Translating this into clinical practice, below, after describing our methods, we report our results and discuss the key pathobiochemical points of COVID-19 pathogenesis and their clinical applications.

\section{Methods}

We used the sci.AI machine reasoning system to operate on publicly available datasets from nlm.nih.gov and Europe PMC. The process consisted of several steps. The first step was to arbitrarily recognize universal biochemical entities and how they relate to each other. The second step was to build a subset of findings that appear to be relevant to COVID-19 pathogenesis. We progressively refined the knowledge and, ultimately, in the last step, linked these excerpts to synthesize pathobiochemical pathways to help explain the management of COVID-19.

\section{Results and Discussion}

Basic life processes require glucose metabolism, through oxidation, into energy, in the form of adenosine triphosphate (ATP). As depicted in Fig.2, during metabolic oxidative processes, electrons are transferred forming oxidants as a normal byproduct, and this occurs in up to $2 \%$ of daily oxygen (O2) consumption. [10] During inflammation, oxidants are produced intentionally as part of a normal immune response. However, increased oxidant production and/or its decreased neutralization result in harmful oxidative excess. There are several exogenous and endogenous factors that affect this condition. 


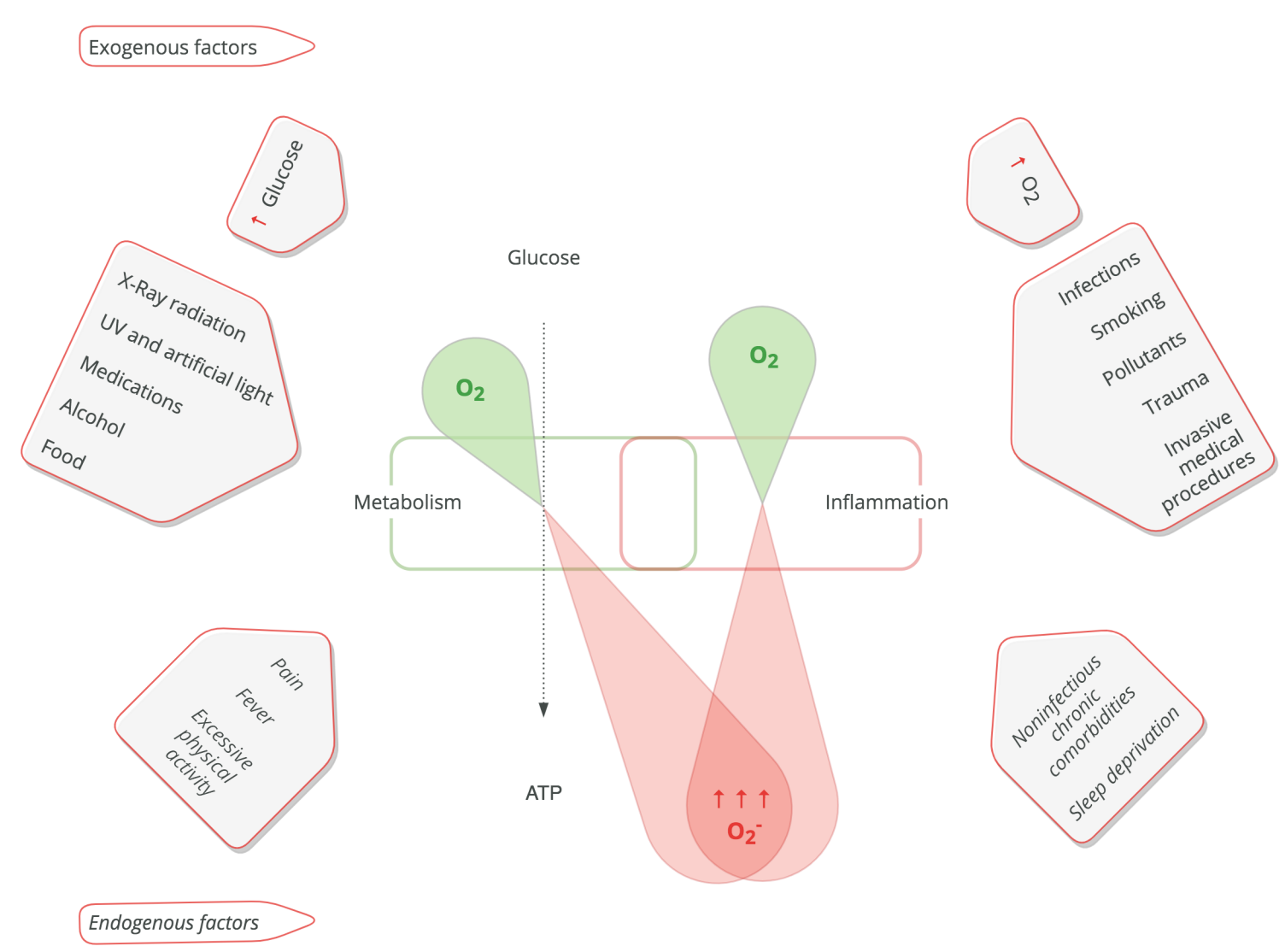

Fig. 2. Factors that increase oxidant production

\section{A. Control of excessive oxidant production (Fig.2)}

Factors that increase oxidant production:

1. Exogenous factors

a) excessive glucose [11]

b) excessive $\mathrm{O} 2[12]$

c) impairment of mitochondrial oxidative phosphorylation by X-Ray [13] and high dose of ultraviolet (UV), infrared (IR) and blue-violet light (screens), [14] ethanol, [15] certain medications and foods [16]

d) triggering of inflammation by physical stresses [17]

2. Endogenous factors

a) increased mitochondrial O2 consumption from pain [18], fever, [19] and excessive physical activity [20]

b) sleep deprivation is accompanied by upregulation of inflammatory cytokine expression [21]

c) triggering of inflammation by metabolites of chronic comorbidities such as obesity, [22] diabetes, [23] hypertension, [24] autoimmune diseases [25] and cancer. [26] 
Whether induced by exogenous or endogenous factors, inflammation is the most potent driver of oxidant production. [27]

Clinical applications: There are several ways to minimize the degree of oxidant production.

- Optimize management of chronic comorbidities.

- Avoid excessive O2 therapy; do not try to achieve the highest possible SpO2 level. [28]

- Avoid hyperglycemia and carbohydrate overfeeding.

- Increase intervals between meals. [29]

- Avoid certain foods such as fava beans, [30] chili pepper, [31] excessive fat [32] and meat. [33]

- Avoid ethanol and the use of other alcohols: the habitual use of alcohol-based hand sanitizers must be deliberately avoided. [34]

- Avoid certain medications such as NSAIDs, [35, 36] hydroxychloroquine [37] and chloroquine, [38] ivermectin, [39] dexamethasone misuse [40] and azithromycin. [41]

- Control fever primarily with physical methods. [42]

- Try to avoid mechanical ventilation unless there is an absolute need. [43]

- Avoid excessive exposure of eyes and skin to sun and artificial lights.

- Minimize exposure to X-Ray radiation by avoiding X-Rays if not absolutely necessary.

- Avoid active and passive smoking. [44]

- Avoid excessive physical activity.

- Mitigate pain primarily with physical methods. [45]

\section{B. Neutralization of excessive oxidants (Fig.3)}

Excessive oxidants are neutralized into nontoxic compounds by antioxidants that can be either exogenous, i.e. those that can be supplemented, or endogenous.

1. Exogenous antioxidants

a) Ascorbic acid (Vit.C), an important water-soluble redox factor that can be synthesized by plants and animals with the notable exception of humans and other higher primates.

b) Carotenoids, fat-soluble pigments in bright red, yellow and orange fruits and vegetables.

c) Polyphenols, secondary metabolites of plants which contribute to their bitterness, astringency, color, flavor, odor and oxidative stability, e.g. flavonoids and coumarines.

d) Vitamin E (Vit.E), a group of fat-soluble compounds found in vegetables and seeds.

e) Glutathione (GSH), the major antioxidant, is synthesized by the body, and is also found in diet and supplements, both sources restoring its endogenous pool.

During oxidant neutralization, exogenous antioxidants are converted to their oxidized form acting as oxidants. And the endogenous antioxidant, GSH, is required for recycling of these oxidized forms back to their antioxidant forms.[46] Therefore, the antioxidant activity of exogenous supplements depends on the antioxidant activity of the endogenous pool.

2. Endogenous antioxidants

a) Superoxide dismutase (SOD) that is dependent on certain co-factors: $\mathrm{Zn}, \mathrm{Cu}$ and $\mathrm{Mn}$.

b) Catalase that is dependent on Fe as a co-factor.

c) Thioredoxin reductase that is dependent on Se as a co-factor.

d) The GSH complex. 

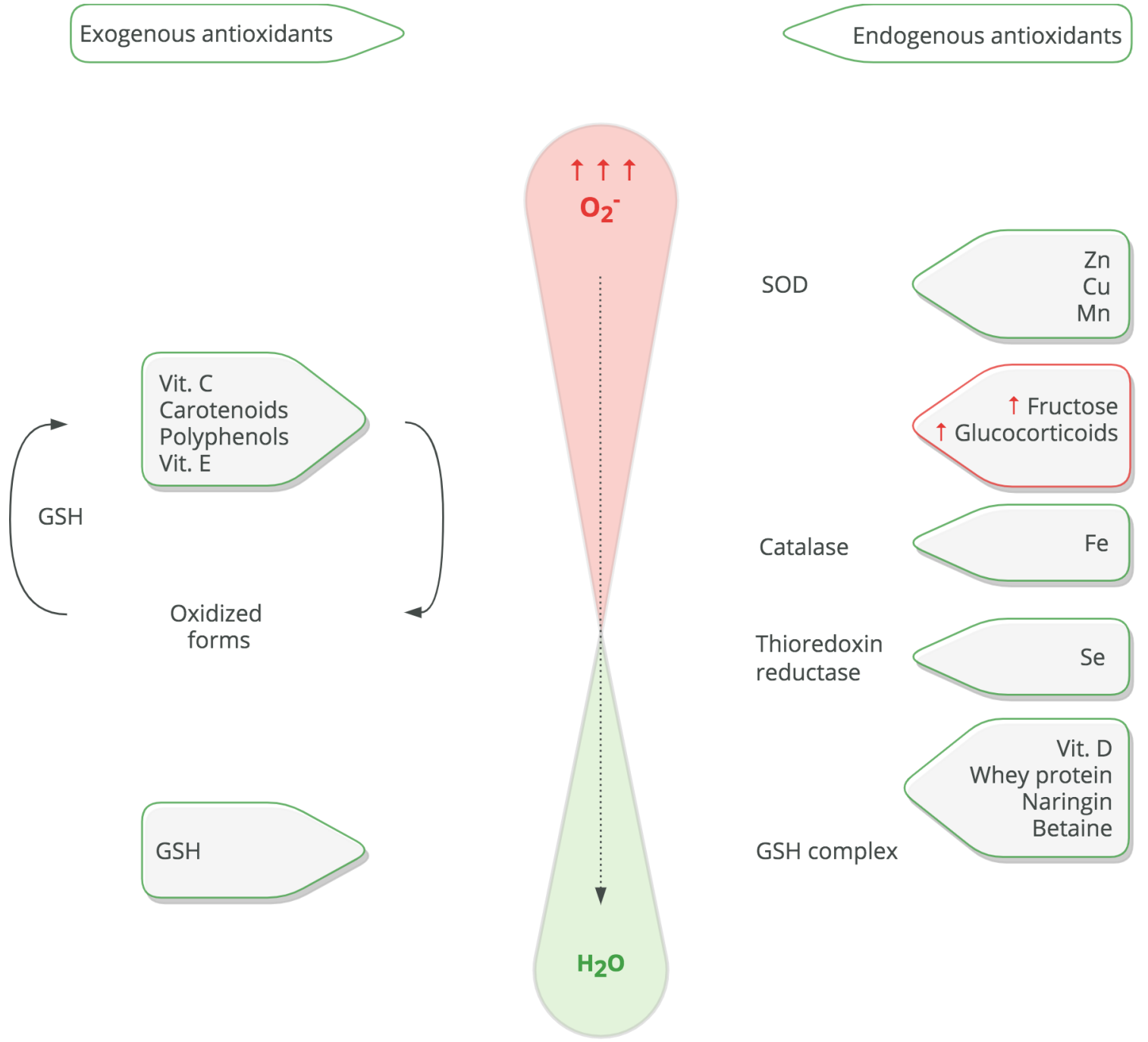

Fig. 3. Factors that affect oxidant neutralization

Factors that interfere with their function include congenital or acquired pathology of the AO system, e.g. G6PD deficiency, and certain supplements. For example, Vit. D, [47] naringin, [48] whey protein, [49] and betaine [50] induce gene expression and activity of endogenous antioxidants. In turn, glucocorticoids and fructose in high doses inhibit it. [50, 51]

The GSH complex (Fig.4) is the main component of the AO system. It is composed of GSH, glutathione peroxidase (GP), glutathione reductase (GR) and the oxidized form of GSH (GSSG). There are certain factors that affect the synthesis and recycling of GSH:

1. GSH synthesis

a) GSH is synthesized from three amino acids: glutamate, cysteine and glycine. 


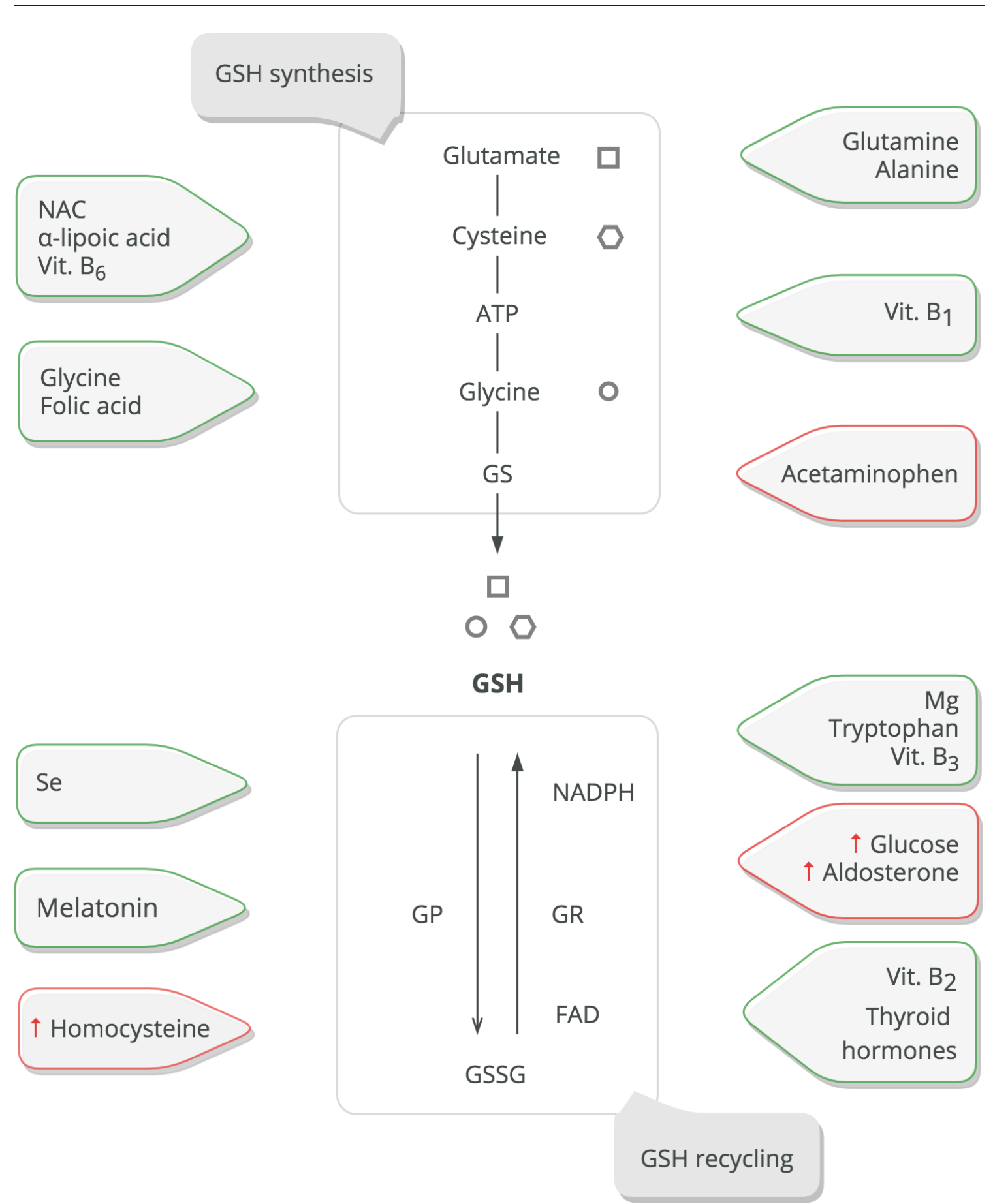

Fig. 4. Factors that affect GSH synthesis and recycling 
b) Glutamate is synthesized from alanine and glutamine which is decreased during inflammatory conditions. [52]

c) Cysteine synthesis requires vit. B6 (pyridoxine) as a co-factor and n-acetylcysteine (NAC) and $\alpha$-lipoic acid as precursors. [53]

d) Glycine synthesis from serine requires folic acid. [54]

e) The GSH synthesis process is energy-dependent that requires ATP and vit. B1 (thiamine) is a co-factor that up-regulates metabolism for ATP production. [55]

f) Acetaminophen inhibits enzyme glutathione synthase (GS). [56]

2. GSH recycling

a) During oxidant neutralization, GSH is oxidized to GSSG by GP that requires Se as a cofactor.

b) Melatonin increases activity of GP. [57]

c) Increased homocysteine levels inhibit GP and folic acid with vit. B12 are co-factors for homocysteine control. [58, 59]

d) GR recycles GSSG back to GSH and is dependent on co-factors, NADPH and flavin adenine dinucleotide (FAD). [60]

e) Vit. B3 (niacin) is a precursor and $\mathrm{Mg}$ is a co-factor for NADPH production. [61, 62]

f) SARS-CoV-2 inhibits absorption of tryptophan, a precursor of niacin and melatonin, through ACE2 suppression in the small intestine. [63]

g) Increased aldosterone levels decrease G6PD level. [64]

h) Hyperglycemia aggravates insulin resistance increasing G6PD deficit. [65]

i) Thyroid hormones and vit. B2 (riboflavin) are co-factors for FAD production. [66]

Clinical applications: There are a number of ways to increase the neutralization of excessive oxidants.

1. Several antioxidants, co-factors and precursors can be supplied exogenously by diet and/or supplements:

- Plants and mushrooms are natural sources of exogenous antioxidants, dose of which matters. In small doses, they work as antioxidants and, in high doses, they can overload the regenerative capacity of endogenous antioxidants and work as oxidants. [67] In addition, anti-nutrients such as fructose have dose-dependent effects as well.

- Ascorbic acid can be administered IV in critically ill patients. [68]

- Microelements: Zn, Cu, Mn, Fe, Se and Mg supplied in sufficient amounts. [69]

- Vit. B1 (thiamine) can be administered IV in critically ill patients. [70]

- Vit. D, B6 (pyridoxine), B2 (riboflavin), B12 (cyanocobalamin), folic acid, $\alpha$-lipoic acid and amino acids supplied in sufficient amounts. [71]

- NAC and glutathione (GSH) can be administered orally, IV or nebulized. [72, 73]

- Vit. B3 (niacin) supplements administered during convalescence to support the AO system. $[74,75]$

2. Avoid chronic use and high doses of glucocorticoids.

3. Avoid acetaminophen. [76]

4. Tight control of thyroid hormones. [77]

5. Tight control of blood glucose levels. [78]

6. Optimize management of chronic comorbidities. 


\section{Upregulation of NO production (Fig.5)}

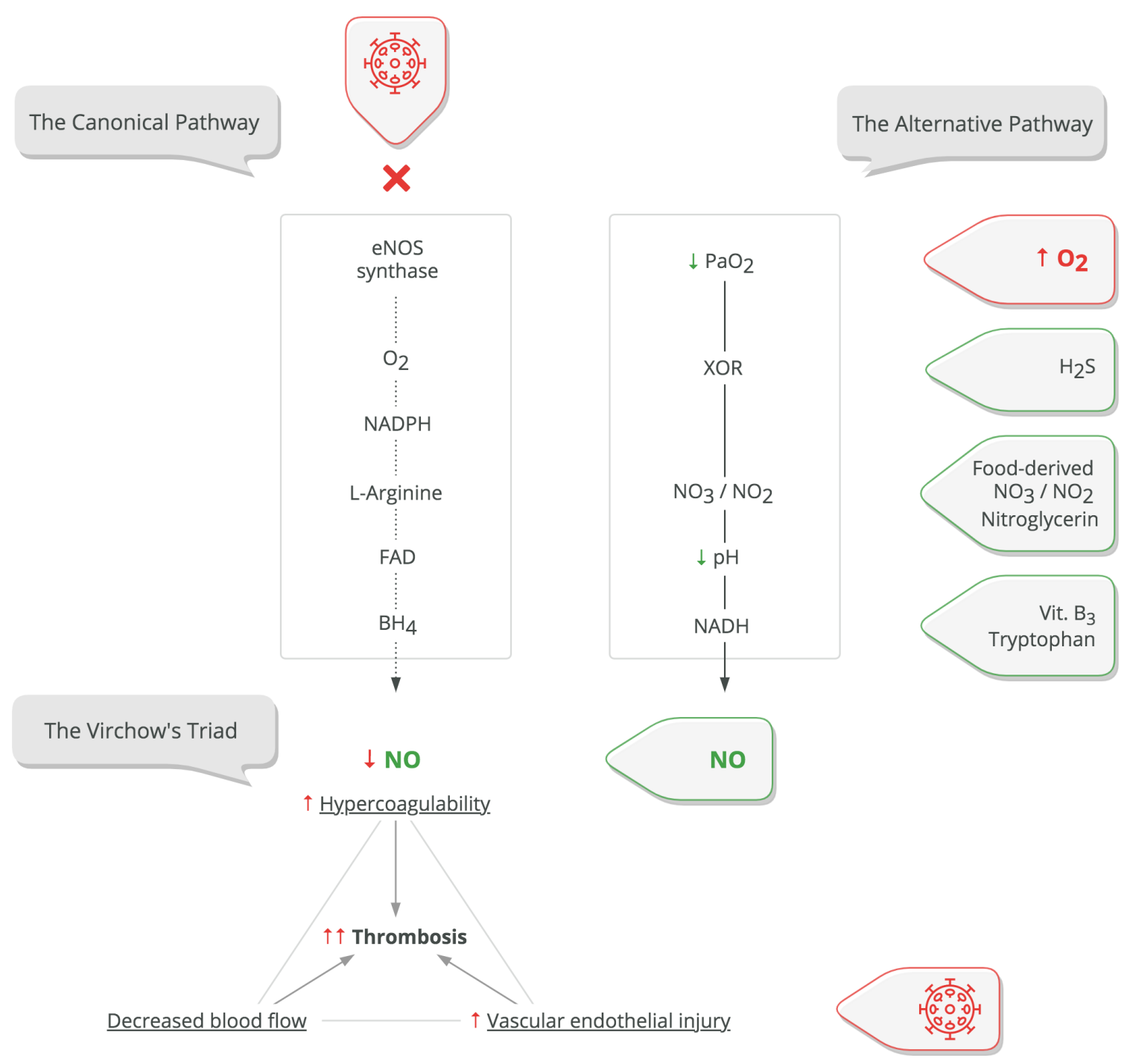

Fig. 5. Factors that affect NO production and the Virchow's Triad

Physiologically, vascular NO has three main roles:

1. As a vasodilatator, it maintains relaxation of blood vessels.

2. As an antioxidant, it inhibits NADPH oxidase, as depicted in Fig.1.

3. As an anticoagulant, as depicted in Fig. 5, NO affects the Virchow's Triad of thrombosis.

As mentioned above, SARS-CoV-2 suppresses NO production increasing hypercoagulability. Moreover, common to other pathogens, SARS-CoV-2 injures vascular endothelial cells. These processes 
predispose to thrombosis which is a major clinical complication of COVID-19. [79] Additionally, as an antiviral, NO suppresses SARS-CoV-2 replication through inhibition of protease activity. [80]

Under normal conditions, vascular NO is produced in two ways, by: [81]

1. The Canonical pathway, through eNOS synthase. It requires tetrahydrobiopterin (BH4) that is a derivative of folic acid, arginine, O2, NADPH and FAD. [82] It is inhibited by SARS-CoV-2.

2. The Alternative pathway, through reductase activity of xanthine oxidoreductase (XOR). It requires nitrates/nitrites (NO3/NO2), the reduced form of nicotinamide adenine dinucleotide (NADH) and is potentiated by acidosis $(\downarrow \mathrm{pH})$ and hypoxemia $(\downarrow \mathrm{PaO} 2)$. [83] XOR is activated by sulfur compounds such as hydrogen sulfide (H2S). [84]

Importantly, COVID-19-induced oxidative stress can increase the levels of methemoglobin which makes SpO2 calculation inaccurate. [85] It falsely causes a low SpO2 by pulse oximetry in patients with a normal $\mathrm{PaO}$. [86] This can be misleading and can result in an unnecessary administration of $\mathrm{O} 2$ and suppression of the rescuing XOR pathway. [87]

Clinical applications: The goal is to reduce the Virchow's Triad to prevent thrombosis by:

1. Restoring NO to decrease hypercoagulability. NO can be supplied exogenously and/or produced through the alternative pathway:

- Boost NO3/NO2 which can be supplied by diet, e.g. beetroot and spinach, [88] and through supplements, e.g. nitroglycerin. [89]

- Avoid excessive O2 therapy; do not try to achieve the highest possible SpO2 level.

- Do not correct acidosis unless it is severe or associated with cardiovascular compromise.

- Boost tryptophan and vit. B3, as precursors of NADH.

- Boost sulfur compounds which can be supplied by a diet rich in allium vegetables such as garlic and onions. [90]

2. Maintaining blood flow through:

- Avoiding increases in blood viscosity with adequate hydration based on urine output. [91]

- Promotion of blood circulation by active and passive movements. [92]

- Supporting ventilation and perfusion of all West's lung zones by breathing exercises and prone positioning. [93, 94]

3. Controlling the degree of oxidative stress to decrease vascular endothelial injury through therapeutic interventions that minimize oxidant production and induce its neutralization.

\section{Conclusion}

In order to mitigate the excessive immune response and not to aggravate it, key pathobiochemical points of COVID-19 pathogenesis enable to apply the essential minimum: the dose makes the poison, Dosis sola facit venenum.

\section{Acknowledgments}

We would like to express our appreciation to The g6pd Deficiency Foundation, Inc. (g6pdDF.org) and The Task Force for their initiatives in education of G6PD Deficiency pertaining to the COVID19 Global Pandemic. 


\section{References}

1. Buinitskaya, Yuliya; Gurinovich, Roman; Wlodaver, Clifford G.; Kastsiuchenka, Siarhei (2020): Highlights of COVID-19 Pathogenesis. Insights into Oxidative Damage. figshare. Preprint. https://doi.org/10.6084/m9.figshare.12121575.v11

2. Buinitskaya Y, Gurinovich R, Wlodaver CG and Kastsiuchenka S (2020) Centrality of G6PD in COVID-19: The Biochemical Rationale and Clinical Implications. Front. Med. 7:584112. doi: $10.3389 /$ fmed.2020.584112

3. Miesel R, Hartung R, Kroeger H. Priming of NADPH oxidase by tumor necrosis factor alpha in patients with inflammatory and autoimmune rheumatic diseases. Inflammation. 1996;20(4):427-438. doi:10.1007/BF01486744

4. Selemidis S, Dusting GJ, Peshavariya H, Kemp-Harper BK, Drummond GR. Nitric oxide suppresses NADPH oxidase-dependent superoxide production by S-nitrosylation in human endothelial cells. Cardiovasc Res. 2007;75(2):349-358. doi:10.1016/j.cardiores.2007.03.030

5. Hecker PA, Leopold JA, Gupte SA, Recchia FA, Stanley WC. Impact of glucose-6-phosphate dehydrogenase deficiency on the pathophysiology of cardiovascular disease. Am J Physiol Heart Circ Physiol. 2013;304(4):H491-H500. doi:10.1152/ajpheart.00721.2012

6. Li Y, Chen M, Cao H, Zhu Y, Zheng J, Zhou H. Extraordinary GU-rich single-strand RNA identified from SARS coronavirus contributes an excessive innate immune response. Microbes Infect. 2013;15(2):88-95. doi:10.1016/j.micinf.2012.10.008

7. Fang W, Jiang J, Su L, et al. The role of NO in COVID-19 and potential therapeutic strategies. Free Radic Biol Med. 2021;163:153-162. doi:10.1016/j.freeradbiomed.2020.12.008

8. Hotamisligil GS, Shargill NS, Spiegelman BM. Adipose expression of tumor necrosis factor-alpha: direct role in obesity-linked insulin resistance. Science. 1993;259(5091):87-91. doi:10.1126/science.7678183

9. Liu H, Zhang D, Zhao B, Zhao J. Superoxide anion, the main species of ROS in the development of ARDS induced by oleic acid. Free Radic Res. 2004;38(12):1281-1287. doi:10.1080/10715760400006940

10. Chance B, Sies H, Boveris A. Hydroperoxide metabolism in mammalian organs. Physiol Rev. 1979;59(3):527-605. doi:10.1152/physrev.1979.59.3.527

11. Russell JW, Golovoy D, Vincent AM, et al. High glucose-induced oxidative stress and mitochondrial dysfunction in neurons. FASEB J. 2002;16(13):1738-1748. doi:10.1096/fj.01-1027com

12. Murphy MP. How mitochondria produce reactive oxygen species. Biochem J. 2009;417(1):1-13. doi:10.1042/BJ20081386

13. Saenko IuV, Shutov AM, Napalkova SM. [X-ray irradiation stimulates the mitochondrial-dependent generation of reactive oxygen and nitrogen species in K562 leukemia cells]. Radiats Biol Radioecol. 2011 Nov-Dec;51(6):677-83. Russian. PMID: 22384717.

14. Vandersee S, Beyer M, Lademann J, Darvin ME. Blue-violet light irradiation dose dependently decreases carotenoids in human skin, which indicates the generation of free radicals. Oxid Med Cell Longev. 2015;2015:579675. doi:10.1155/2015/579675

15. González A, Pariente JA, Salido GM. Ethanol stimulates ROS generation by mitochondria through $\mathrm{Ca} 2+$ mobilization and increases GFAP content in rat hippocampal astrocytes. Brain Res. 2007;1178:2837. doi:10.1016/j.brainres.2007.08.040

16. Kanner J, Selhub J, Shpaizer A, Rabkin B, Shacham I, Tirosh O. Redox homeostasis in stomach medium by foods: The Postprandial Oxidative Stress Index (POSI) for balancing nutrition and human health. Redox Biol. 2017;12:929-936. doi:10.1016/j.redox.2017.04.029

17. Li F, Xu M, Wang M, et al. Roles of mitochondrial ROS and NLRP3 inflammasome in multiple ozone-induced lung inflammation and emphysema. Respir Res. 2018;19(1):230. Published 2018 Nov 22. doi:10.1186/s12931-018-0931-8

18. Ackerman WE 3rd, Molnar JM, Juneja MM. Beneficial effect of epidural anesthesia on oxygen consumption in a parturient with adult respiratory distress syndrome. South Med J. 1993;86(3):361364. doi:10.1097/00007611-199303000-00023 
19. Schumacker PT, Rowland J, Saltz S, Nelson DP, Wood LD. Effects of hyperthermia and hypothermia on oxygen extraction by tissues during hypovolemia. J Appl Physiol (1985). 1987;63(3):1246-1252. doi:10.1152/jappl.1987.63.3.1246

20. Nagasawa T. Effect of exercise intensity on oxygen consumption kinetics in non-exercising muscle during exercise. Clin Physiol Funct Imaging. 2012;32(3):172-178. doi:10.1111/j.1475-097X.2011.01073.x

21. Pandey AK, Kar SK. REM sleep deprivation of rats induces acute phase response in liver. Biochem Biophys Res Commun. 2011;410(2):242-246. doi:10.1016/j.bbrc.2011.05.123

22. Yang S, Zhu H, Li Y, et al. Mitochondrial adaptations to obesity-related oxidant stress. Arch Biochem Biophys. 2000;378(2):259-268. doi:10.1006/abbi.2000.1829

23. Merdzo I, Rutkai I, Sure VNLR, Katakam PVG, Busija DW. Effects of prolonged type 2 diabetes on mitochondrial function in cerebral blood vessels. Am J Physiol Heart Circ Physiol. 2019;317(5):H1086H1092. doi:10.1152/ajpheart.00341.2019

24. Puddu P, Puddu GM, Cravero E, De Pascalis S, Muscari A. The putative role of mitochondrial dysfunction in hypertension. Clin Exp Hypertens. 2007;29(7):427-434. doi:10.1080/10641960701613852

25. Di Dalmazi G, Hirshberg J, Lyle D, Freij JB, Caturegli P. Reactive oxygen species in organ-specific autoimmunity. Auto Immun Highlights. 2016;7(1):11. doi:10.1007/s13317-016-0083-0

26. Rice CM, Davies LC, Subleski JJ, et al. Tumour-elicited neutrophils engage mitochondrial metabolism to circumvent nutrient limitations and maintain immune suppression. Nat Commun. 2018;9(1):5099. Published 2018 Nov 30. doi:10.1038/s41467-018-07505-2

27. Mills EL, Kelly B, Logan A, et al. Succinate Dehydrogenase Supports Metabolic Repurposing of Mitochondria to Drive Inflammatory Macrophages. Cell. 2016;167(2):457-470.e13. doi:10.1016/j.cell.2016.08.064

28. Dhont S, Derom E, Van Braeckel E, Depuydt P, Lambrecht BN. The pathophysiology of 'happy' hypoxemia in COVID-19. Respir Res. 2020;21(1):198. Published 2020 Jul 28. doi:10.1186/s12931-020$01462-5$

29. Van Dyck L, Vanhorebeek I, Wilmer A, et al. Towards a fasting-mimicking diet for critically ill patients: the pilot randomized crossover ICU-FM-1 study. Crit Care. 2020;24(1):249. Published 2020 May 24. doi:10.1186/s13054-020-02987-3

30. Fava Beans. In: Drugs and Lactation Database (LactMed). Bethesda (MD): National Library of Medicine (US); December 3, 2018.

31. Yang KM, Pyo JO, Kim GY, et al. Capsaicin induces apoptosis by generating reactive oxygen species and disrupting mitochondrial transmembrane potential in human colon cancer cell lines. Cell Mol Biol Lett. 2009;14(3):497-510. doi:10.2478/s11658-009-0016-2

32. Vial G, Dubouchaud H, Couturier K, et al. Effects of a high-fat diet on energy metabolism and ROS production in rat liver. J Hepatol. 2011;54(2):348-356. doi:10.1016/j.jhep.2010.06.044

33. Carvalho AM, Miranda AM, Santos FA, Loureiro AP, Fisberg RM, Marchioni DM. High intake of heterocyclic amines from meat is associated with oxidative stress. Br J Nutr. 2015;113(8):1301-1307. doi:10.1017/S0007114515000628

34. Atolani O, Baker MT, Adeyemi OS, et al. COVID-19: Critical discussion on the applications and implications of chemicals in sanitizers and disinfectants. EXCLI J. 2020;19:785-799. Published 2020 Jun 15. doi:10.17179/excli2020-1386

35. Fujikawa I, Ando T, Suzuki-Karasaki M, Suzuki-Karasaki M, Ochiai T, Suzuki-Karasaki Y. Aspirin Induces Mitochondrial Ca2+ Remodeling in Tumor Cells via ROS-Depolarization-Voltage-Gated Ca2+ Entry. Int J Mol Sci. 2020;21(13):4771. Published 2020 Jul 5. doi:10.3390/ijms21134771

36. Husain MA, Sarwar T, Rehman SU, Ishqi HM, Tabish M. Ibuprofen causes photocleavage through ROS generation and intercalates with DNA: a combined biophysical and molecular docking approach. Phys Chem Chem Phys. 2015;17(21):13837-13850. doi:10.1039/c5cp00272a

37. Wang LF, Lin YS, Huang NC, et al. Hydroxychloroquine-inhibited dengue virus is associated with host defense machinery. J Interferon Cytokine Res. 2015;35(3):143-156. doi:10.1089/jir.2014.0038

38. Ganguli A, Choudhury D, Datta S, Bhattacharya S, Chakrabarti G. Inhibition of autophagy by chloroquine potentiates synergistically anti-cancer property of artemisinin by promoting ROS dependent apoptosis. Biochimie. 2014;107 Pt B:338-349. doi:10.1016/j.biochi.2014.10.001

Page 12 of 15 
39. Zhang P, Zhang Y, Liu K, et al. Ivermectin induces cell cycle arrest and apoptosis of HeLa cells via mitochondrial pathway. Cell Prolif. 2019;52(2):e12543. doi:10.1111/cpr.12543

40. Luan G, Li G, Ma X, et al. Dexamethasone-Induced Mitochondrial Dysfunction and Insulin ResistanceStudy in 3T3-L1 Adipocytes and Mitochondria Isolated from Mouse Liver. Molecules. 2019;24(10):1982. Published 2019 May 23. doi:10.3390/molecules24101982

41. Jiang X, Baucom C, Elliott RL. Mitochondrial Toxicity of Azithromycin Results in Aerobic Glycolysis and DNA Damage of Human Mammary Epithelia and Fibroblasts. Antibiotics (Basel). 2019;8(3):110. Published 2019 Aug 3. doi:10.3390/antibiotics8030110

42. Salgado PO, Silva LC, Silva PM, Chianca TC. Physical methods for the treatment of fever in critically ill patients: a randomized controlled trial. Rev Esc Enferm USP. 2016;50(5):823-830. doi:10.1590/S0080623420160000600016

43. Kavazis AN, Talbert EE, Smuder AJ, Hudson MB, Nelson WB, Powers SK. Mechanical ventilation induces diaphragmatic mitochondrial dysfunction and increased oxidant production. Free Radic Biol Med. 2009;46(6):842-850. doi:10.1016/j.freeradbiomed.2009.01.002

44. Sarkar R, Kishida S, Kishida M, et al. Effect of cigarette smoke extract on mitochondrial hememetabolism: An in vitro model of oral cancer progression. Toxicol In Vitro. 2019;60:336-346. doi:10.1016/j.tiv.2019.06.016

45. Şahin N, Karahan AY, Albayrak İ. Effectiveness of physical therapy and exercise on pain and functional status in patients with chronic low back pain: a randomized-controlled trial. Turk J Phys Med Rehabil. 2017;64(1):52-58. Published 2017 Aug 9. doi:10.5606/tftrd.2018.1238

46. Sotler R, Poljšak B, Dahmane R, et al. PROOXIDANT ACTIVITIES OF ANTIOXIDANTS AND THEIR IMPACT ON HEALTH. Acta Clin Croat. 2019;58(4):726-736. doi:10.20471/acc.2019.58.04.20

47. Tohari AM, Alhasani RH, Biswas L, et al. Vitamin D Attenuates Oxidative Damage and Inflammation in Retinal Pigment Epithelial Cells. Antioxidants (Basel). 2019;8(9):341. Published 2019 Aug 24. doi:10.3390/antiox8090341

48. Wali AF, Rashid S, Rashid SM, et al. Naringenin Regulates Doxorubicin-Induced Liver Dysfunction: Impact on Oxidative Stress and Inflammation. Plants (Basel). 2020;9(4):550. Published 2020 Apr 24. doi:10.3390/plants9040550

49. Xu R, Liu N, Xu X, Kong B. Antioxidative effects of whey protein on peroxide-induced cytotoxicity. J Dairy Sci. 2011;94(8):3739-3746. doi:10.3168/jds.2010-3891

50. Ganesan B, Anandan R, Lakshmanan PT. Studies on the protective effects of betaine against oxidative damage during experimentally induced restraint stress in Wistar albino rats. Cell Stress Chaperones. 2011;16(6):641-652. doi:10.1007/s12192-011-0276-4

51. Zhao W, Devamanoharan PS, Varma SD. Fructose induced deactivation of antioxidant enzymes: preventive effect of pyruvate. Free Radic Res. 2000;33(1):23-30. doi:10.1080/10715760000300581

52. Cruzat VF, Pantaleão LC, Donato J Jr, de Bittencourt PI Jr, Tirapegui J. Oral supplementations with free and dipeptide forms of L-glutamine in endotoxemic mice: effects on muscle glutamine-glutathione axis and heat shock proteins. J Nutr Biochem. 2014;25(3):345-352. doi:10.1016/j.jnutbio.2013.11.009

53. Lu SC. Regulation of glutathione synthesis. Mol Aspects Med. 2009;30(1-2):42-59. doi:10.1016/j.mam.2008.05.005

54. Tjong E, Dimri M, Mohiuddin SS. Biochemistry, Tetrahydrofolate. [Updated 2020 Aug 31]. In: StatPearls [Internet]. Treasure Island (FL): StatPearls Publishing; 2021 Jan-. Available from: https://www.ncbi.nlm.nih.gov/books/NBK539712/

55. Gralak MA, Dębski B, Drywień M. Thiamine deficiency affects glucose transport and -oxidation in rats. J Anim Physiol Anim Nutr (Berl). 2019;103(5):1629-1635. doi:10.1111/jpn.13146

56. Walker V, Mills GA, Anderson ME, et al. The acetaminophen metabolite N-acetyl-p-benzoquinone imine (NAPQI) inhibits glutathione synthetase in vitro; a clue to the mechanism of 5-oxoprolinuric acidosis?. Xenobiotica. 2017;47(2):164-175. doi:10.3109/00498254.2016.1166533

57. Swiderska-Kołacz G, Klusek J, Kołataj A. The effect of melatonin on glutathione and glutathione transferase and glutathione peroxidase activities in the mouse liver and kidney in vivo. Neuro Endocrinol Lett. 2006;27(3):365-368. 
58. Handy DE, Zhang Y, Loscalzo J. Homocysteine down-regulates cellular glutathione peroxidase (GPx1) by decreasing translation. J Biol Chem. 2005;280(16):15518-15525. doi:10.1074/jbc.M501452200

59. Nozari E, Ghavamzadeh S, Razazian N. The Effect of Vitamin B12 and Folic Acid Supplementation on Serum Homocysteine, Anemia Status and Quality of Life of Patients with Multiple Sclerosis. Clin Nutr Res. 2019;8(1):36-45. Published 2019 Jan 25. doi:10.7762/cnr.2019.8.1.36

60. Berkholz DS, Faber HR, Savvides SN, Karplus PA. Catalytic cycle of human glutathione reductase near 1 A resolution. J Mol Biol. 2008;382(2):371-384. doi:10.1016/j.jmb.2008.06.083

61. Makarov MV, Trammell SAJ, Migaud ME. The chemistry of the vitamin B3 metabolome. Biochem Soc Trans. 2019;47(1):131-147. doi:10.1042/BST20180420

62. Lendzian KJ. Interactions between magnesium ions, $\mathrm{pH}$, glucose-6-phosphate, and NADPH/NADP $(+)$ ratios in the modulation of chloroplast glucose-6-phosphate dehydrogenase in vitro. Planta. 1978;141(1):105-110. doi:10.1007/BF00387751

63. Ferreira-Duarte M, Estevinho MM, Duarte-Araújo M, Magro F, Morato M. Unraveling the Role of ACE2, the Binding Receptor for SARS-CoV-2, in Inflammatory Bowel Disease. Inflamm Bowel Dis. 2020;26(12):1787-1795. doi:10.1093/ibd/izaa249

64. Leopold JA, Dam A, Maron BA, et al. Aldosterone impairs vascular reactivity by decreasing glucose-6phosphate dehydrogenase activity [published correction appears in Nat Med. 2009 Sep;15(9):1093]. Nat Med. 2007;13(2):189-197. doi:10.1038/nm1545

65. Zhang Z, Liew CW, Handy DE, et al. High glucose inhibits glucose-6-phosphate dehydrogenase, leading to increased oxidative stress and beta-cell apoptosis. FASEB J. 2010;24(5):1497-1505. doi:10.1096/fj.09136572

66. Cimino JA, Jhangiani S, Schwartz E, Cooperman JM. Riboflavin metabolism in the hypothyroid human adult. Proc Soc Exp Biol Med. 1987;184(2):151-153. doi:10.3181/00379727-184-42459

67. Bouayed J, Bohn T. Exogenous antioxidants-Double-edged swords in cellular redox state: Health beneficial effects at physiologic doses versus deleterious effects at high doses. Oxid Med Cell Longev. 2010;3(4):228-237. doi:10.4161/oxim.3.4.12858

68. Liu F, Zhu Y, Zhang J, Li Y, Peng Z. Intravenous high-dose vitamin C for the treatment of severe COVID-19: study protocol for a multicentre randomised controlled trial. BMJ Open. 2020;10(7):e039519. Published 2020 Jul 8. doi:10.1136/bmjopen-2020-039519

69. Dharmalingam K, Birdi A, Tomo S, et al. Trace Elements as Immunoregulators in SARS-CoV-2 and Other Viral Infections [published online ahead of print, 2021 Feb 12]. Indian J Clin Biochem. 2021;1-11. doi:10.1007/s12291-021-00961-6

70. Branco de Oliveira MV, Irikura S, Lourenço FHB, et al. Encephalopathy responsive to thiamine in severe COVID-19 patients. Brain Behav Immun Health. 2021;14:100252. doi:10.1016/j.bbih.2021.100252

71. Jovic TH, Ali SR, Ibrahim N, et al. Could Vitamins Help in the Fight Against COVID-19?. Nutrients. 2020;12(9):2550. Published 2020 Aug 23. doi:10.3390/nu12092550

72. Liu Y, Wang M, Luo G, et al. Experience of N-acetylcysteine airway management in the successful treatment of one case of critical condition with COVID-19: A case report. Medicine (Baltimore). 2020;99(42):e22577. doi:10.1097/MD.0000000000022577

73. Horowitz RI, Freeman PR, Bruzzese J. Efficacy of glutathione therapy in relieving dyspnea associated with COVID-19 pneumonia: A report of 2 cases. Respir Med Case Rep. 2020;30:101063. Published 2020 Apr 21. doi:10.1016/j.rmcr.2020.101063

74. Jones HD, Yoo J, Crother TR, et al. Nicotinamide exacerbates hypoxemia in ventilatorinduced lung injury independent of neutrophil infiltration [published correction appears in PLoS One. 2015;10(5):e0128735]. PLoS One. 2015;10(4):e0123460. Published 2015 Apr 13. doi:10.1371/journal.pone.0123460

75. Doroftei B, Ilie OD, Cojocariu RO, et al. Minireview Exploring the Biological Cycle of Vitamin B3 and Its Influence on Oxidative Stress: Further Molecular and Clinical Aspects. Molecules. 2020;25(15):3323. Published 2020 Jul 22. doi:10.3390/molecules25153323

76. Sestili P, Fimognari C. Paracetamol-Induced Glutathione Consumption: Is There a Link With Severe COVID-19 Illness?. Front Pharmacol. 2020;11:579944. Published 2020 Oct 7. doi:10.3389/fphar.2020.579944 
77. Wang W, Su X, Ding Y, et al. Thyroid Function Abnormalities in COVID-19 Patients. Front Endocrinol (Lausanne). 2021;11:623792. Published 2021 Feb 19. doi:10.3389/fendo.2020.623792

78. Wu J, Huang J, Zhu G, et al. Elevation of blood glucose level predicts worse outcomes in hospitalized patients with COVID-19: a retrospective cohort study. BMJ Open Diabetes Res Care. 2020;8(1):e001476. doi:10.1136/bmjdrc-2020-001476

79. Kerbikov O, Orekhov P, Borskaya E, Nosenko N. High incidence of venous thrombosis in patients with moderate-to-severe COVID-19. Int J Hematol. 2021;113(3):344-347. doi:10.1007/s12185-020-03061-y

80. Akaberi D, Krambrich J, Ling J, et al. Mitigation of the replication of SARS-CoV-2 by nitric oxide in vitro. Redox Biol. 2020;37:101734. doi:10.1016/j.redox.2020.101734

81. Peleli M, Zollbrecht C, Montenegro MF, et al. Enhanced XOR activity in eNOS-deficient mice: Effects on the nitrate-nitrite-NO pathway and ROS homeostasis. Free Radic Biol Med. 2016;99:472484. doi:10.1016/j.freeradbiomed.2016.09.004

82. Förstermann U, Sessa WC. Nitric oxide synthases: regulation and function. Eur Heart J. 2012;33(7):829837d. doi:10.1093/eurheartj/ehr304

83. Cantu-Medellin N, Kelley EE. Xanthine oxidoreductase-catalyzed reduction of nitrite to nitric oxide: insights regarding where, when and how. Nitric Oxide. 2013;34:19-26. doi:10.1016/j.niox.2013.02.081

84. Pardue S, Kolluru GK, Shen X, et al. Hydrogen sulfide stimulates xanthine oxidoreductase conversion to nitrite reductase and formation of NO. Redox Biol. 2020;34:101447. doi:10.1016/j.redox.2020.101447

85. Naymagon L, Berwick S, Kessler A, Lancman G, Gidwani U, Troy K. The emergence of methemoglobinemia amidst the COVID-19 pandemic. Am J Hematol. 2020;95(8):E196-E197. doi:10.1002/ajh.25868

86. Dickinson A, Gianniosis M, Riaz R, Lande L. COVID-19 EXPOSING GLUCOSE-6-PHOSPHATE DEHYDROGENASE DEFICIENCY WITH METHEMOGLOBINEMIA: A CASE REPORT. Chest. 2020;158(4):A891. doi:10.1016/j.chest.2020.08.829

87. Kapil V, Khambata RS, Jones DA, et al. The Noncanonical Pathway for In Vivo Nitric Oxide Generation: The Nitrate-Nitrite-Nitric Oxide Pathway. Pharmacol Rev. 2020;72(3):692-766. doi:10.1124/pr.120.019240

88. Lidder S, Webb AJ. Vascular effects of dietary nitrate (as found in green leafy vegetables and beetroot) via the nitrate-nitrite-nitric oxide pathway. Br J Clin Pharmacol. 2013;75(3):677-696. doi:10.1111/j.13652125.2012.04420.x

89. Daxon BT, Lark E, Matzek LJ, Fields AR, Haselton KJ. Nebulized Nitroglycerin for Coronavirus Disease 2019-Associated Acute Respiratory Distress Syndrome: A Case Report. A A Pract. 2021;15(2):e01376. Published 2021 Feb 5. doi:10.1213/XAA.0000000000001376

90. Hine C, Zhu Y, Hollenberg AN, Mitchell JR. Dietary and Endocrine Regulation of Endogenous Hydrogen Sulfide Production: Implications for Longevity. Antioxid Redox Signal. 2018;28(16):1483-1502. doi:10.1089/ars.2017.7434

91. Belasco R, Edwards T, Munoz AJ, Rayo V, Buono MJ. The Effect of Hydration on Urine Color Objectively Evaluated in CIE L*a*b* Color Space. Front Nutr. 2020;7:576974. Published 2020 Oct 26. doi:10.3389/fnut.2020.576974

92. Kiss G, Faludi B, Szilágyi B, et al. Effect of Active and Passive Mechanical Thromboprophylaxis and Consensual Effect on the Venous Blood Flow Velocity Among Hemiparetic Patients. Clin Appl Thromb Hemost. 2019;25:1076029619832111. doi:10.1177/1076029619832111

93. Prisk GK, Yamada K, Henderson AC, et al. Pulmonary perfusion in the prone and supine postures in the normal human lung. J Appl Physiol (1985). 2007;103(3):883-894. doi:10.1152/japplphysiol.00292.2007

94. Mezidi M, Guérin C. Effects of patient positioning on respiratory mechanics in mechanically ventilated ICU patients. Ann Transl Med. 2018;6(19):384. doi:10.21037/atm.2018.05.50 